\title{
La marca de las bestias. Mercancía, propiedad y territorio entre los pobladores mapuche de zonas rurales de Chubut y Río Negro
}

The mark of the Beasts.Merchandise, property and territory among Mapuche settlers in rural areas of Chubut and Río Negro

\section{Hernán Horacio Schiaffini}

\section{(2) OpenEdition \\ Journals}

\section{Edición electrónica}

URL: http://journals.openedition.org/corpusarchivos/2944

DOI: $10.4000 /$ corpusarchivos.2944

ISSN: 1853-8037

Editor

Diego Escolar

\section{Referencia electrónica}

Hernán Horacio Schiaffini, « La marca de las bestias. Mercancía, propiedad y territorio entre los

pobladores mapuche de zonas rurales de Chubut y Río Negro », Corpus [En línea], Vol. 9, No 1 | 2019,

Publicado el 30 junio 2019, consultado el 04 julio 2019. URL : http://journals.openedition.org/ corpusarchivos/2944; DOI : 10.4000/corpusarchivos.2944

Este documento fue generado automáticamente el 4 julio 2019. 


\section{La marca de las bestias. Mercancía, propiedad y territorio entre los pobladores mapuche de zonas rurales de Chubut y Río Negro}

The mark of the Beasts.Merchandise, property and territory among Mapuche settlers in rural areas of Chubut and Río Negro

Hernán Horacio Schiaffini

\section{NOTA DEL EDITOR}

Fecha de recepción del original: 09/01/2019

Fecha de aceptación para publicación: 30/05/2019

\section{Introducción}

1 Dice Marx en El Capital (2006 [1872]) que las mercancías son cosas y "no pueden ir por sí solas al mercado" ni "intercambiarse ellas mismas" (2006: 103). Por eso hay que prestar atención a "sus custodios, los poseedores de mercancías".

Para vincular estas cosas entre sí como mercancías, los custodios de las mismas deben relacionarse mutuamente como personas cuya voluntad reside en dichos objetos, de tal suerte que el uno, sólo con acuerdo de la voluntad de otro, o sea mediante un acto voluntario común a ambos, va a apropiarse de la mercancía ajena al enajenar la propia. Los dos, por consiguiente, deben reconocerse el uno al otro como propietarios privados. Esta relación jurídica, cuya forma es el contrato legalmente formulado o no-, es una relación entre voluntades en la que se refleja la relación económica [Las cursivas son del original] (Marx, 2006: 103). 
2 El ganado, o bien sus derivados como la carne o la lana, son mercancías que no pueden ir solas al mercado. Aquí queremos hacernos ciertas preguntas en torno del proceso social de constitución de sus propietarios privados. Pero también queremos exponer algunas características y tensiones que emergen del proceso de registro del ganado, enfocándonos principalmente en pobladores mapuche de zonas rurales de Chubut y Río Negro en la actualidad. Como veremos, el problema desborda la mera constitución de mercancías legales y sus propietarios privados para adentrarse en las dinámicas de la producción doméstica, los recovecos de la burocracia, los dispositivos de control policial y los reclamos políticos y territoriales de las organizaciones mapuche.

En este texto abordaremos entonces el problema de las marcas y señales y algunos de sus sentidos desde la perspectiva de los pobladores mapuche de diferentes parajes del noroeste de Chubut, sudoeste de Río Negro y zonas de meseta y estepa sobre la llamada "Línea Sur", también en Río Negro. Dichas dimensiones tienen que ver con la vida cotidiana y familiar, con los trámites burocráticos, legales y administrativos, con la producción económica, el territorio y las luchas políticas.

4 Nuestro abordaje ha sido desarrollado primordialmente mediante la práctica etnográfica en los últimos dos años. Pero también retomamos registros de años anteriores. ${ }^{1} \mathrm{~A}$ ello hemos sumado entrevistas pautadas con algunos funcionarios estatales y la indagación documental en torno de los marcos legales y operacionales del sistema de marcas y señales.

El registro de propiedad del ganado se ejerce en Chubut y Río Negro -como en todas las otras provincias argentinas, con sus variantes- a través del sistema de marcas y señales según ordena la ley nacional de Marcas y Señales $\mathrm{N}^{\circ} 22.939$. En Chubut la ley provincial que adhiere a dicha ley es la $\mathrm{N}^{\circ} 4.113$. En Río Negro es la $\mathrm{N}^{\circ} 1.645$. Describiremos más abajo algunos detalles de la ley así como en qué consiste materialmente el proceso de marcar o señalar.

\section{"Crianceros" mapuche en la Patagonia: territorio e historia}

6 La población mapuche de Río Negro y Chubut se aproxima a las 70.000 personas según el Censo Nacional de $2010 .^{2}$ De este total, cerca de un 20\% - es decir, unas 15.000 personasviven en el ámbito rural.

7 Se trata, por lo general, de productores con predios pequeños para las escalas de las unidades productivas de la zona, que muchas veces apelan a la trashumancia entre áreas de veranada e invernada para mantener a sus animales. ${ }^{3}$ Se los ha llamado "crianceros" (Bendini, Tsakoumagkos y Nogues, 2004) y han sido catalogados como parte de la "agricultura familiar" (PROINDER, 2013). Desde la óptica de la antropología económica se los concibe como "unidades domésticas de producción" (Balazote y Radovich, 1995). "Paisanos", "pobladores", "productores" son otros rótulos dados por sus vecinos o por las autoridades locales. Los pobladores mapuche de los parajes rurales de Río Negro y Chubut se dedican principalmente a la cría de lanares y caprinos de manera extensiva, en predios de muy baja productividad. ${ }^{4}$ Suelen complementar sus recursos con ingresos extraprediales, a veces de manera determinante y ser objeto de distintas políticas públicas de desarrollo y/o asistencia por parte de diferentes agencias de Estado. 
Históricamente, se trata de una población que mantuvo una situación de soberanía y autonomía (Bechis, 2010) respecto de los Estados nacionales de Argentina y Chile hasta fines del siglo XIX, cuando fue incorporada de manera violenta a través de la ocupación militar desarrollada mediante las llamadas "Campañas al Desierto" en Argentina y "Pacificación de la Araucanía" en Chile.

En aquél momento los nacientes Estados nacionales buscaban, entre otros objetivos, el control efectivo del territorio al que aspiraban, el establecimiento de las fronteras y la expansión de la frontera ganadera (principalmente el desplazamiento de ovinos) y la incorporación de los grandes territorios de la Pampa y el sur del continente al circuito productivo del mercado mundial.

10 Para ponerlo en términos sintéticos, por cuestiones de espacio, diremos que luego de la acción de los Ejércitos, los pueblos originarios de Norpatagonia sufrieron la pérdida de su autonomía y el control de sus medios de reproducción: la tierra fue enajenada y grandes porciones apropiadas por nuevos actores: en principio soldados y grandes compañías comerciales locales y extranjeras cuyo presencia fue fomentada por diversas políticas estatales, aun careciendo de sistematicidad (Briones y Delrio, 2002). Muchas familias indígenas fueron separadas y relocalizadas. Sus instituciones políticas fueron desarticuladas y se vieron forzados a recomponerlas en condiciones impuestas, utilizando los márgenes de acción que las nuevas condiciones posibilitaron (Delrio, 2005).

11 Se dio lugar a un proceso lento de reconstrucción comunal, en principio bajo las formas de "colonias agrícolas" o "reservas indígenas". En otros casos directamente sin figura legal que les amparara. De tal manera recomenzaron prácticas productivas y reproductivas que debieron anclarse forzosamente en un contexto radicalmente transformado, con nuevas relaciones de propiedad e instituciones políticas impuestas.

12 Es decir, el avance de la sociedad argentina sobre los pueblos originarios de Norpatagonia no se limitó a la acción militar, sino que extendió sus efectos tanto en el tiempo como hacia otras dimensiones, que lo abarcan y atraviesan globalmente. En este texto intentaremos precisar en algunos aspectos que se vinculan a la pequeña producción ganadera y los distintos dispositivos de intervención que se ejercen sobre las marcas y señales.

13 Todos estos procesos históricos, como verificaremos hacia el final de este texto, continúan sosteniendo un vínculo efectivo con las situaciones de falta de reconocimiento actuales y con los reclamos y disputas que sostienen las organizaciones mapuche en, al menos, las provincias de Río Negro y Chubut. Son el origen histórico de las situaciones que abordaremos. Aquí indagaremos, entre otras cosas, cómo el sistema de marcas y señales permite establecer una ligazón entre los problemas de la producción (entendida en su más amplio sentido, como producción social de la vida y los lazos sociales), el reconocimiento legal y territorial, la autonomía política y la regulación estatal.

\section{El sistema de marcas y señales}

14 Los antecedentes del sistema de marcas y señales son antiguos. En Santa Fe y Córdoba hay registros de marcas que datan de 1575 y 1585, respectivamente (Maiztegui Martinez, 2017). La abundancia de pasturas, la existencia de ganado cimarrón y la falta o la precaria delimitación de los predios, sumada a la característica del ganado de ser un objeto móvil, hacían de imponer una marca sobre el cuerpo de los animales una necesidad para la 
regulación de la propiedad, aun en el marco de una centralización estatal débil. Los mismos productores necesitaban tener control sobre su propiedad.

En los años previos a la llamada "Organización Nacional", el uso de marcas estaba muy extendido, aunque se continuaba careciendo de una regulación centralizada. El Código Rural de la Provincia de Buenos Aires, redactado por Valentín Alsina y sancionado en 1865 , intentó sistematizar el sistema de marcas y señales tomando como antecedente los "usos y costumbres" de los ganaderos. Pocos años más tarde, en 1869, el Código Civil redactado por Dalmacio Vélez Sarsfield fortaleció esta dirección, aunque generando un debate doctrinario en torno de las "marcas" o la "posesión" como factor definitorio de la propiedad (Martínez Golletti, 2005). En 1885 se sanciona un Código Rural en Córdoba y en 1901 otro en Santa Fe. ${ }^{5}$

En la actualidad, como dijimos, la ley nacional que regula el uso de las marcas y señales es la $\mathrm{N}^{\circ} 22.939$. En su primer artículo expresa directamente que:

Artículo $1^{\circ}$ : La marca es la impresión que se efectúa sobre el animal de un dibujo o diseño, por medio de hierro candente, de marcación en frío, o de cualquier otro procedimiento que asegure la permanencia en forma clara e indeleble que autorice la Secretaría de Agricultura y Ganadería.

La señal es un corte o incisión, o perforación o grabación hecha a fuego, en la oreja del animal.

Y más adelante:

Artículo $5^{\circ}$ : Es obligatorio para todo propietario de ganado mayor o menor, tener registrado a su nombre el diseño que empleare para marcar o señalar [....]

Queda prohibido marcar o señalar sin tener registrado el diseño que se emplee, con la excepción de la señal que fuera usada como complemento de la marca en el ganado mayor.

Artículo $6^{\circ}$ : Es obligatorio para todo propietario de hacienda marcar su ganado mayor y señalar su ganado menor. En los ejemplares de pura raza, la marca o señal podrá ser sustituida por tatuajes o reseñas, según especies.

En una rápida observación queda claro que: a) las marcas y señales son signos que literalmente se imponen sobre el cuerpo de los animales, b) que cada propietario debe tener registrada a su nombre la marca y señal que utiliza y c) que es obligatorio marcar y/ o señalar a los animales.

Las marcas y señales juegan un papel importante para constituir al ganado o sus frutos (carnes, cueros, lanas o pelo) en mercancías legalmente reconocidas: son aquellos signos, estatalmente administrados, que garantizan el vínculo entre las cosas y sus custodios, los poseedores de mercancías o los propietarios privados.

21 Pero la regulación legal no se limita solamente a este aspecto, sino que también incluye los movimientos en el espacio del ganado-mercancía. Tal y como señalaba Marx, las cosas no pueden ir solas al mercado, así que los custodios deben acreditar su propiedad en caso de traslado. Esto se hace mediando la expedición de "guías" de transporte:

Artículo $16^{\circ}$ : Para la licitud del tránsito de ganado, es obligatorio el uso de guía, expedida en la forma que establezcan las disposiciones locales. La validez de la guía y su régimen, serán juzgados de acuerdo a las leyes de la provincia en que fuera emitida.

La "guía" no es otra cosa que un documento que certifica el nombre del dueño de los animales, las marcas y/o señales que llevan impresas en sus cuerpos, su estado sanitario, los puntos de partida y destino del viaje, el tipo de vehículo en que se trasladan, e incluso 
debe dar lugar a una intervención policial que indique a qué establecimiento pertenecen los animales, en qué departamento y ubicación catastral se encuentran, qué tipo de animales están viajando y con qué finalidad.

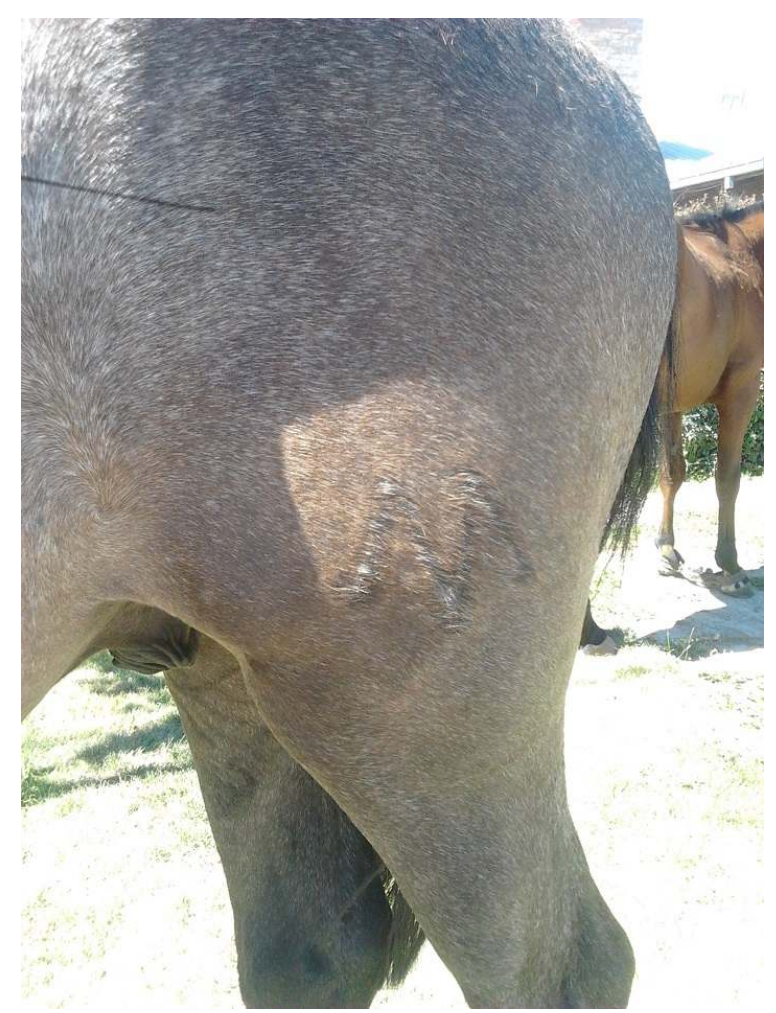

Imagen 1: Ejemplo de una marca a fuego en el anca de un equino. Foto: Hernán Schiaffıni

Como vemos, marcar, señalar o trasladar animales abre un amplio abanico de posibilidades y actores que entran en juego y tienen su parte en la producción y realización de estas mercancías. Intentaremos más adelante avanzar con claridad sobre estas distintas variables.

\section{Marcas y significantes}

Una marca es un signo, algo que "reemplaza alguna cosa para alguien" según la conocida fórmula de Charles S. Peirce, recordada por Lévi-Strauss (2006, p. 15). Una señal también es un signo.

En su dimensión material, una marca es una quemadura sobre el cuerpo de un animal, ${ }^{6}$ con determinada forma (suelen ser las iniciales del propietario, cruzadas o superpuestas) que se imprime así de manera permanente. Una señal es un tajo o una serie tajos o perforaciones en las orejas de las ovejas y cabras. 


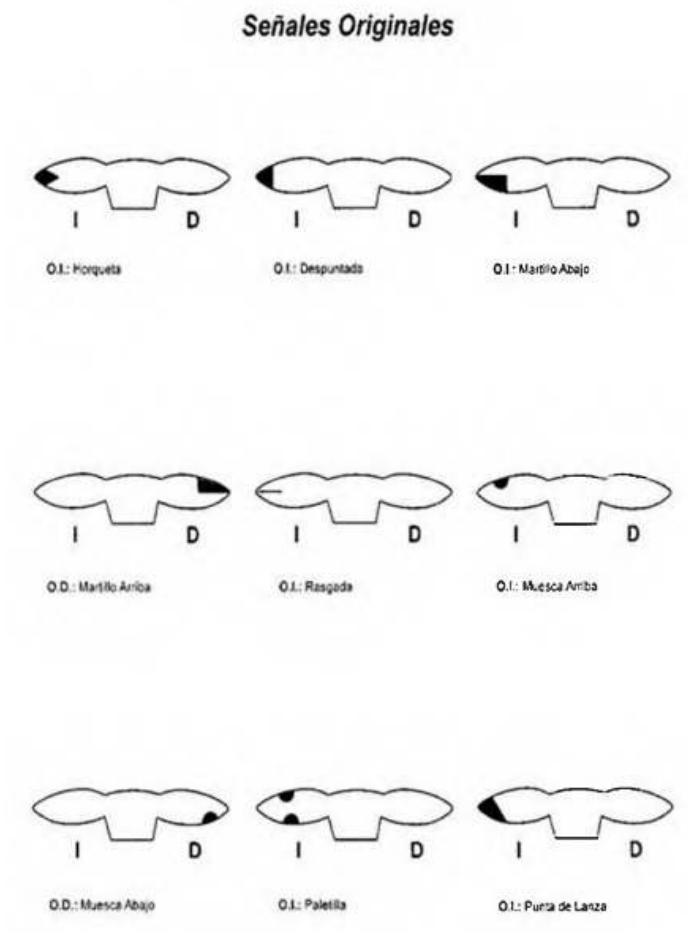

Imagen 2 : Ejemplos de señales para las orejas de ovinos y caprinos, según el Catálogo de Diseños de Señales de Chubut, 2004. Ministerio de la Producción.

El animal puede estar marcado o no estarlo. El productor puede tener registrada una señal a su nombre o no tenerla. En este punto, las marcas y señales son unidades discretas, se tienen o no se tienen.

En otro plano, la dimensión material del signo conforma la dimensión significante (de Saussure, 1945). Se trata del cuerpo del signo, el soporte de su significado. Esto quiere decir que las marcas y señales son los soportes de diferentes significados.

Se puede analizar, entonces, a las marcas en su dimensión significante y también a las marcas en cuanto a lo que significan.

Debemos advertir que los signos -en este caso las marcas y señales- no tienen un significado único, sino que varían de acuerdo a quién los interpreta, desde qué posición y en qué contexto. Además, cada significado o sentido que podemos descubrir puede remitir, a su vez, a otras cadenas significantes; abriendo ramificaciones a veces imprevisibles para actores situados en coordenadas de sentido distantes.

Por tanto, intentaremos a continuación describir y analizar las marcas y señales desde su dimensión significante y, en un segundo lugar, interpretar algunos de sus significados intentando situarlos en su contexto y en las formas en que se manifiestan. En dichos procesos de interpretación se evidenciarán, como veremos, complejas redes que son a veces contradictorias y expresan, en simultáneo, alianzas, tensiones, conflictos o pujas en torno de la familia y la vecindad, los procesos económicos y políticos, el rol del Estado o los reclamos en torno de la autonomía y la autodeterminación del pueblo mapuche. 


\section{La "marcación": ciclo familiar, parentesco y economía doméstica}

31 La marcación es el acontecimiento anual en que los crianceros de nuestra zona (el noroeste de Chubut y sudoeste de Río Negro) imponen su marca a los animales que han nacido desde la última marcación próxima pasada. En ocasiones se aprovecha para hacer simultáneamente la señalada, el proceso análogo pero para imponer señales. Se hace, entonces, "marcación y señalada".

32 Llevar adelante la marcación y la señalada está precedido por un buen conjunto de trámites burocráticos. Como el Juez de Paz (en Chubut) o la Dirección de Ganadería (en Río Negro) tienen que habilitar el procedimiento, es necesario cumplir con todos los requisitos que las instituciones demandan (los enumeraremos en el apartado acerca de las implicancias legales y burocráticas de la marca).

33 Pero una vez que se logra y la marcación se lleva adelante, el resultado es un evento de trabajo colectivo que adquiere posteriormente carácter festivo. Parientes y amigos son invitados a participar y en ocasiones viajan largos kilómetros para estar presentes. Los vecinos también son invitados $\mathrm{y}$, además de participar del acontecimiento, pueden ver con sus propios ojos que los dueños de casa marcan solamente el ganado que les pertenece.

34 A continuación transcribiremos algunas notas de campo que describen una marcación -esa vez no hubo señalada- en casa de una familia mapuche ubicada en las proximidades de El Maitén, en Chubut. El registro fue realizado en el año 2016 y, si bien da cuenta de las peculiaridades del caso, también expresa de manera cabal la generalidad del proceso.

Hay quince enlazadores distribuidos en un llano bastante amplio, que no está cerrado ni alambrado, esperando la salida del ternero. Los animales están separados en dos corrales contiguos, divididos por una tranquera.

Dos hombres dentro del corral eligen al ternero siguiente, lo persiguen y lo empujan hacia fuera. Apenas pisa el exterior del corral comienzan a lloverle lazos, que trata de esquivar mientras corre buscando una ilusoria libertad. Los enlazadores usan lazos de cuero con un nudo móvil en el extremo y arrojan siempre a los pies del animal, tratando de hacer que pise dentro del círculo formado por el nudo, para así cerrarlo con velocidad y atraparlo.

Pero no es tarea fácil. El ternero saltica, elude, cambia de dirección. Los lazos no logran su objetivo, los recogen y vuelven a volar.

Al final una de las patas termina atrapada. Mientras el enlazador tironea para retenerlo, otros hombres que están cerca lo voltean sobre un costado. Enseguida lo manean, le atan las patas juntas y ya la marca al rojo vivo, que estaba esperando en la fogata, vuela y se deposita sobre el cuarto trasero del pobre animal. Se escucha un fuerte mugido de queja y se siente olor a pelo y a carne quemada. Después lo desatan y lo dejan ir. Se prepara la salida del siguiente animal.

En esta parte son todos varones trabajando, aunque algunos son niños. Toman cerveza, que distribuye L., que es el dueño de la casa y de los animales. Es un anciano que fue un domador famoso en su juventud, pero ahora no puede hacer estos trabajos de gran exigencia física. Está sentado junto al fogón donde se calienta la marca y entre sus piernas tiene varias botellas de cerveza. Se las da a uno de sus nietos, un muchachito de 12 o 13 años, para que les lleve de beber a los hombres que están enlazando. A modo de reconocimiento y premio, primero que todos toma quien logró enlazar al último animal. Ch., el hijo mayor, quien se hará cargo del 
campo y de la producción, es quien lleva y trae la marca, ayuda a manear y marca efectivamente, pero no enlaza.

Cuando se termina de marcar es hora de la jineteada de novillos. Ya ha pasado el mediodía, no queda nada por hacer salvo divertirse. Los eligen en el corral y los empujan afuera entre cinco o seis personas, jalándolo de la cola y de las narices. Después lo aprietan desde los lados y lo mantienen quieto para que suba el jinete. Cuatro o cinco jóvenes se animan, Ch. entre ellos, y ruedan al poco rato.

En tanto, atrás de la casa se cocinaba asado con cuero. El encargado era el yerno de L. Cuando terminó el trabajo y la jineteada nos reunimos todos en torno del fuego y comemos. Somos alrededor de cincuenta, la mayoría jóvenes y también hay mujeres y niños. La mayoría son de El Maitén, amigos y conocidos de Ch. De hecho, hay gente que L. no conoce. Ch. es ya, evidentemente, la cabeza del hogar en lo práctico. Los vecinos no vinieron. Estaban avisados con tiempo, pero no vinieron. Tenían que firmar (y lo hicieron) una notificación y tenían que reconocer la marca, pero no vinieron al encuentro. No están en las mejores relaciones con los dueños de casa.

Después de comer, algunos juegan a la taba. La cancha está delimitada entre algunos árboles frutales detrás del fogón donde se cocinó el asado. Es un charquito de barro en el suelo, donde la taba cae. Algunos están bebiendo desde temprano. Con la comida tomamos bastante vino y la sobremesa se hace bebiendo.

Pasa Ch. con un sombrero en la mano, haciendo una vaca para comprar cerveza. Bajan al pueblo a comprar y vuelven después con varios cajones. Con ellos llegan acordeones y guitarras y enseguida están los músicos tocando. Son buenos, tocan chamamé. Recién al rato una pareja sale a bailar, y poco después el verdadero baile habrá comenzado.

Como se puede percibir, la marcación implica un evento que tiene amplias ramificaciones y que puede dar lugar a una multiplicidad de análisis desde diferentes perspectivas. Las amistades y alianzas sociales, los lazos que se afianzan o se resquebrajan por diferentes tipos de disputas (la presencia/ausencia en la marcación pueden funcionar como índice de las buenas/malas relaciones), la retribución del trabajo aportado mediante la forma del alimento compartido... son todas situaciones y procesos que se anclan, de una $u$ otra manera, en las marcas y señales que se imponen en una marcación o una señalada.

En tanto significante, la marca es la quemadura en el cuerpo del animal. Pero como significado aquí presenta al mundo de las móviles alianzas y confrontaciones vecinales. En la marca misma está encarnada, para estas personas, el evento festivo-laboral de la marcación y el entramado de relaciones de parentesco, compadrazgo y amistad que implica.

Examinemos otro sentido de la marca en el siguiente ejemplo, basado en anotaciones realizadas durante trabajo en terreno en otra comunidad mapuche del noroeste de Chubut hacia 2010:

Alfredo tenía su marca colgando de un clavo, del lado externo de una de las paredes de la casa. Era un fierro de cerca de un metro, con una empuñadura de madera en un extremo y sus iniciales forjadas en el otro, dentro de un óvalo. La había mandado a hacer por un herrero y no era barata. Era nueva y nos las mostraba contento.

Hasta ahora los animales tenían la marca de su padre. Si se lo piensa un poco no es difícil entender que para un joven tener una marca propia señala el inicio de su vida económica independiente: podrá tener sus animales, designarlos con su nombre. Una marca, al igual que las señales que imprime, debe estar registrada en el libro de marcas y señales del juez de paz. Esto acarrea una serie de requisitos, desde certificados de vacunación de animales hasta guías de transporte y permisos de señal. Cuando se hace marcación y señalada (por lo general durante los primeros días del año) hay que avisar a los vecinos para que encierren sus animales, y también se los invita a la fiesta, para que ayuden y para que vean que no se marca nada que no 
corresponda. Las marcas no pueden repetirse dentro de un radio de cincuenta kilómetros. Por tanto, en el hierro que imprimirá las iniciales del propietario en el cuerpo de los animales descansa un complejo entramado de disposiciones estatales y concepciones subyacentes de propiedad.

La marca de Alfredo implica que ahora él es parcialmente responsable de todos esos procedimientos. Por eso, cuando Alfredo empuña su marca, no está empuñando un simple objeto metálico, sino que está alzando y mostrando su propio futuro. Y no es una cuestión de animales, nada más. Establecerse independientemente, hacer la propia casa, $\mathrm{u}$ ocupar la casa de los padres una vez que han envejecido y no pueden hacerse cargo del campo, suele ir de la mano con la conformación de una familia propia. Ése era, por lo menos, el plan de Alfredo.

Hacía tiempo tenía la promesa de una muchacha de la comunidad. Ella era menor que él, entonces esperaron. Las familias eran pocas allí, así que se podía llegar a calcular quién se juntaría con quién, a menos que se fueran al pueblo. Las dos familias eran amigas, los hermanos de ella conocían y compartían actividades con Alfredo.

Cuando pareció haber llegado el momento, Alfredo comprendió la necesidad de contar con un mínimo ahorro ("capital"- decía él) propio para empezar. Habría que comprar animales, materiales, estar preparado para proveer si llegaban hijos.

No hay muchos medios para conseguir una cantidad de dinero más o menos significativa para gente como Alfredo. Hay que vender animales (a veces malvender, pero Alfredo ni para eso tenía), conseguir un trabajo estatal (cosa que sólo algunos pocos afortunados logran y requiere de estudios primarios y secundarios completos) o irse a la esquila. Ésta fue la opción lógica.

Alfredo se sumó a una comparsa y pasó cuatro meses esquilando en distintas estancias del sur de Chubut y de Santa Cruz. La comparsa se componía de cerca de una decena de trabajadores, que viajaban en un colectivo junto con los instrumentos de trabajo y los víveres que se les vendían: yerba, tabaco, alcohol. Los precios exorbitantes de estas mercancías hacían que quien no se cuidara perdiera buena parte de su sueldo antes de cobrarlo y trabajara para cancelar la cuenta del almacén.

El ritmo de trabajo era infernal, desde la mañana hasta la noche. Imaginemos llegar a una estancia que tiene cuarenta o cincuenta mil cabezas lanares que hay que esquilar en una semana. Cuando se termina en un lugar, hay que emprender viaje y seguir en otro, enfrentándose con otra marea de ovejas que balan mientras son peladas. Dormían en los mismos galpones donde trabajaban y el único descanso era cuando llovía, porque no se puede esquilar la lana mojada.

Alfredo fue cuidadoso. No jugaba y se cuidaba con la bebida, así que pudo volver con algo de dinero, a lo sumo unos diez mil pesos - tras cuatro meses de trabajo-. ${ }^{7}$

Sin embargo, lo esperaba una decepción. Su novia ya no estaba. Se había ido con un muchacho de otro pueblo a vivir en el puesto de una estancia lejana. Se encontró de pronto con su marca, con su capital y sin mujer.

Hizo reclamos, las familias se enemistaron, pero no hubo forma de deshacer lo hecho. La muchacha estaba haciendo su vida con otro. Herido, Alfredo juntó los animales de su familia y partió al campo de veranada, varias horas sierra arriba de su casa, donde pasaría, solo, los siguientes cinco meses.

En este ejemplo los significantes siguen siendo las marcas y señales. Pero los significados son distintos que en el ejemplo anterior. Tanto las dinámicas del ciclo familiar como las lógicas de la herencia se hacen evidentes en lo recién relatado. El crecimiento de la familia, las nuevas alianzas matrimoniales y el (potencial) surgimiento o transformación de una nueva unidad doméstica se enlazan con la necesidad de un mínimo ahorro y una marca propia. El significado de la marca contenía, aunque en este caso se truncase, un proyecto familiar y un intento de independencia económica. 


\section{Legalidad, burocracia y dispositivos de control} (art. 9 de la ley 1.645). elegirá uno).

"La marca es como el DNI ${ }^{8}$ del animal. Es como la patente 9 del animal", nos dijo una funcionaria entrevistada en la etapa exploratoria de esta investigación.

La metáfora, aunque quizás forzada, es útil. La marca implica un registro -en nuestro caso toma la forma de gruesos libros, algunos de varias décadas de antigüedad, donde están asentados los dibujos de la marcas y señales y los datos que se les asocian- y vinculado a ello, un sistema burocrático que administra los pedidos nuevos, los cambios, las compra-ventas, las bajas y las solicitudes de tránsito.

El sistema de marcas y señales da entonces lugar a un complejo y relativamente sistemático conjunto de personificaciones que intervienen sobre el mismo. Desde la perspectiva de sus funciones podemos distinguir al menos dos niveles, además del legislativo: una esfera burocrática que se encarga de la implementación de los pasos del registro y emisiones de los boletos de marca y señal y que está representada por los Juzgados de Paz en Chubut y las Direcciones de Ganadería en Río Negro; ${ }^{10}$ y otra que se dedica a las funciones de control respecto del tránsito de ganado y el robo del mismo, lugar que ocupan las policías provinciales (en Chubut hay incluso una división de la policía que se especializa en "Abigeato" y en Río Negro existen las "Brigadas Rurales").

\section{Requisitos legales para la obtención de boleto de marca o señal}

Como señalamos al inicio, la ley $\mathrm{N}^{\circ} 4.113$ regula el sistema de marcas y señales en Chubut y la No 1.645 hace lo propio para Río Negro. Respectivamente establecen que el Registro General de Marcas y Señales, en coordinación con los Juzgado de Paz en un caso y las Direcciones de Ganadería en coordinación con los municipios en el otro, sean los encargados de implementar las disposiciones de las leyes provinciales.

Por tanto, el ámbito legislativo deposita en estos cuerpos burocráticos los procedimientos de registro de marcas y señales, emisión de boletos, autorización de marcaciones y señaladas, emisión de guías de transporte y cobro de tasas respectivas. También, y no es menor, en Río Negro deposita en dichas entidades la capacidad de interpretación de la ley

Para que un productor, mapuche o no, pueda obtener un boleto de marca o señal (es decir, registrar una marca o señal a su nombre) en Chubut debe presentar: ${ }^{11}$

-a) Identificación Catastral de la ubicación de la explotación.

-b) Condiciones de dominio.

-c) Certificación de animales (cuántos animales y de qué tipo tiene).

-d) Presentación de tres diseños alternativos de marca/señal (el Registro de Marcas

-e) Esperar la opinión del Juez de Paz interviniente.

En tanto, en Río Negro, los requisitos son los siguientes:

-a) Documento Nacional de Identidad

-b) Documento que acredite ser propietario, arrendatario o poseedor de uno o más predios rurales en la provincia.

-c) Comprobante que acredite que es propietario del ganado; Certificado de adquisición, o transmisión de propiedad legalizado. 
-d) Formulario de solicitud.

abre a su vez otro abanico de opciones y trámites, cosa que también ocurre en el caso chubutense. Esto es importante porque tiene consecuencias directas sobre los pobladores mapuche, cuya situación dominial, por lo general, no está regularizada. Citamos directamente del documento al que nos referimos:

La Documentación indicada en el inciso "b)" será la siguiente:

PROPIETARIO: Título de propiedad o Boleto de Compra-Venta, certificado por Autoridad competente o Escribano Público, y copia autenticada del Título de Propiedad.

ARRENDATARIO: Contrato de arrendamiento o constancia expedida por el propietario con las firmas certificadas por Escribano Público, Autoridad Policial, etc; sellado de rentas según corresponda y fotocopia del título de propiedad del predio rural arrendado, debiendo constar los datos de ubicación catastral.

A PASTAJE O PASTOREO: Idem a lo requerido para los arrendatarios.

PERMISIONARIO: Idem a lo requerido para los arrendatarios.

CON AUTORIZACIÓN: Deberá presentar una autorización por escrito del dueño del campo, con la correspondiente certificación de firmas ante autoridad competente o Escribano, indicando los datos catastrales (sección, lote, fracción).

OCUPANTE DE TIERRA FISCAL: Certificado expedido por la Dirección General de Tierras o Delegaciones de la misma o copia autenticada de la Resolución en tal sentido.

Es decir que, si seguimos lo que aquí se indica, el trámite de marca no expone solamente la vinculación entre el ganado y el propietario, sino también entre el propietario y el territorio en que los animales se crían. Las marcas y señales aparecen como significantes no sólo de la propiedad del ganado, sino de la relación de propiedad/no propiedad de la tierra. Como mostraremos más adelante, esta faceta da pie a una serie de conflictos y reclamos por parte de los pobladores y productores mapuche. Básicamente porque muchas comunidades rurales mapuche no tienen regularizada su situación territorial y son tratados por el Estado como "fiscaleros": no cuentan con título de propiedad del campo, pero el título se les requiere para tramitar la marca.

Para obtener el permiso para la marcación, un productor debe también dirigirse a la oficina burocrática correspondiente y presentar una solicitud aclarando quién es, en qué lote, fracción y sección habita y pidiendo permiso para marcar o señalar (o ambos) en determinados día y hora. Debe acompañar la solicitud con la firma de sus vecinos linderos, para certificar que están avisados, y presentar el trámite al menos unos cinco días antes de la marcación o señalada.

En el ámbito de los dispositivos de control, son las policías provinciales los órganos facultados para solicitar y revisar el cumplimiento de estos requisitos. Otras instituciones, como el Servicio Nacional de Sanidad y Calidad Agroalimentaria (SENASA), de orden nacional, se superponen en esta función, aunque por otros motivos: están encargados de la vigilancia respecto de la sanidad animal: vacunaciones, certificados de libre enfermedad, etc. Por cuestiones de espacio y orden de la exposición, no los hemos abordado en el presente texto. ${ }^{12}$

Por lo general, las intervenciones de estas agencias de control, al igual que las policiales, se dan en los caminos, no en los establecimientos de los productores. Como se dijo, para trasladar ganado legalmente, es necesaria la guía de transporte. En el caso de los frutos de la producción (lana, cueros, pelo, carne) también es necesaria una guía, de distinto tipo. 
51 La guía sólo puede ser tramitada después del registro de la marca o señal, es un trámite lógica y cronológicamente posterior debido a motivos obvios: se traslada lo que primero se demostró como propio. Sea en transporte propio o en uno alquilado, cuando los animales o los frutos viajan deben ir acompañados por las guías que certifican la correspondencia con sus marcas o señales. De hecho, al menos en Chubut, la propia solicitud requiere que se le dé aviso a la policía y que la misma firme el papel que, a continuación, deberá autorizar el Juez de Paz.

\section{Marca y economía: mercancías legales, valores de uso y producción de mercancías por medio de bienes}

52 La dimensión económica de la marcación es la rectora de todo el proceso, en tanto es la que permite la articulación entre la producción, el Estado y la esfera legal que hace obligatorio el registro e imposición de la marca.

Una mercancía no es un objeto de origen exclusivamente "capitalista". Se pueden producir mercancías en el marco de relaciones sociales de producción no capitalistas: los campesinos o las unidades domésticas mapuche pueden, por ejemplo, producir algunas cosas destinadas a la venta, o también pueden intentar vender algún excedente aun cuando el destino predominante de su producción sea el auto-abastecimiento o sobrevivan a través de ingresos extraprediales.

Lo que define a una mercancía es estar sujeta a un proceso de compra-venta. Lo que define a una mercancía capitalista también es estar sujeta a un proceso de compra-venta, pero en un contexto donde el carácter predominante de la producción social yace en una separación entre la fuerza de trabajo y la propiedad de los medios de producción. Los trabajadores son individuos formalmente libres que venden su capacidad de trabajo -que se transforma en una mercancía más- a aquellos que detentan la propiedad de los medios y/o objetos de producción. Así, los segundos realizan ganancias sobre la explotación del trabajo de los primeros.

Además, tal proceso está orientado por el intercambio con otras mercancías. Es decir, se lleva adelante una producción (idealmente) destinada a ser vendida y reinvertida como parte de una proceso de acumulación ampliada, y no a ser consumida por sus propios productores directos.

Ahora bien: ¿cómo se entronca este esquema de las personificaciones capitalistas con la dinámica productiva de los "crianceros" mapuche? ¿Cuál es el punto de contacto entre estas dimensiones de la totalidad social?

Pues en tanto productores simples de mercancías, que llevan adelante una apropiación privada $^{13}$ de sus frutos (aun cuando no se constituyan, por lo general, en productores capitalistas) los "crianceros" mapuche requieren, como parte de su propia dinámica productiva, de las marcas y señales como medio de certificación de su propiedad legal.

Y en segunda instancia, para constituirse como propietarios legales de dichas mercancías (ganado y derivados) ante el mercado y otros actores sociales, los "crianceros" mapuche deben asegurar el legítimo vínculo que sostiene su persona social con los animales y con el territorio en que se ubican y reproducen. Tal vínculo, veíamos, se acredita mediante una compleja trama de dispositivos legales, burocráticos y policiales relativos a los títulos de propiedad, los permisos de marca y guías de transporte; y descansa, en última 
instancia, sobre documentaciones que el propio Estado emite. Es decir, el propio Estado se erige en garante de ese "vínculo legítimo".

Ahora bien, si dentro de la dinámica económica es necesario considerar, entonces, tal articulación entre territorio, Estado, producción y marcas, podemos añadir algunas nociones al respecto. Esto permite agregar algunos elementos para pensar la distinción entre "tierra" y "territorio" en el marco de los procesos que atraviesan los pueblos originarios de Patagonia.

\section{A. Gregory y el "bien supremo"}

C. A. Gregory (1997) hizo una distinción pocas veces señalada en el campo de la antropología económica, aún en el análisis de un problema clásico, como es el del don.

61 En contra de la oposición dicotómica habitual entre don (gift) y mercancía (commodities), Gregory plantea la existencia de los bienes (goods) como un tipo de objetos de diferente orden que los anteriores, pero que tienen una incidencia central en las dinámicas de producción, distribución y consumo de las unidades domésticas campesinas (households).

La propuesta presenta algunas semejanzas con aquella planteada por Maurice Godelier en torno de "las cosas que se dan, las cosas que se venden y las cosas que no se dan ni se venden, sino que deben guardarse" (1996, p. 54), retomando largas reflexiones de la antropología en torno de los intercambios no capitalistas. Se recuperan, así, los trabajos de Marcel Mauss (1980 [1925]), Marshall Sahlins (1983) y Annette Weiner (1992), entre otros.

Los dones (gifts) son cosas que se dan. Las mercancías (commodities) son cosas que se venden.

Los bienes (goods) son cosas que no se dan ni se venden, y deben ser guardadas.

Desde esta perspectiva Gregory se apresura a señalar que en el caso de las unidades campesinas, además de posibles talismanes, reliquias $\mathrm{u}$ objetos sagrados que suelen resguardarse del conocimiento de "los de afuera", la tierra (el territorio, se diría desde una perspectiva mapuche) suele ser aquel objeto que no se da ni se vende, sino que debe resguardarse:

In rural areas land tends to be the special subject of affective valuation of this kind.

[...] Examples like this can be drawn all over the world and from all times. [...] This examples signal the argument I want to develop here which is that, in agrarian economy, land is the supreme good (Gregory, 1997, pp. 73-74).

En las áreas rurales la tierra tiende a ser ese sujeto de valoración afectiva especial. [...] Ejemplos como éstos pueden ser tomados de cualquier parte del mundo y de todas las épocas. [...] Ellos apuntan al argumento que quiero desarrollar aquí, y que es que, para las economías agrarias, la tierra es el bien supremo (Gregory, 1997:

73-74. Traducción propia).

La tierra como "bien supremo" no se reduce a ser un "objeto inalienable", un "keepsake" o una reliquia importante: se trata del bien a través del cual se organiza toda la producción, que se erige como eje de un sistema valorativo y afectivo.

Debido a ello, considerando a la tierra como "bien supremo", Gregory señala la importancia de la participación de los bienes dentro del ciclo económico de la unidad doméstica. Ello requiere tanto una breve clarificación de los términos del ciclo productivo como la explicación somera de algunas categorías mapuche. 
67 En efecto, a pesar de no poder desarrollar aquí la cuestión por motivos de espacio, grandes segmentos del pueblo mapuche atraviesan actualmente procesos de recuperación y reconstrucción cultural que se expresan en el lenguaje y las categorizaciones políticas e históricas. En muchas regiones del mundo mapuche no hablamos de "tierra" sino de territorio, de mapu y wall mapu, (términos que designan espacios territoriales que no se reducen al plano de lo extenso, sino que abarcan dimensiones superiores e inferiores del cosmos) de rewe (el espacio ceremonial propio de cada lof, que le permite establecer intercambios con los antepasados y deidades que habitan esos otros planos) y de lof (una unidad familiar-político-territorial articulada mediante el linaje). Lo que expresa que en el territorio se condensan, además de aspectos productivos, afectividades, historia, linaje y relaciones con seres humanos y extra-humanos, entre otras cosas.

En términos del análisis marxista de la economía agraria doméstica, el ciclo económico suele esquematizarse como una dinámica "M - D - M", donde "M" es "mercancía" y "D", "dinero"; o sea que la unidad doméstica produce un objeto que luego intenta intercambiar por dinero. Obtenido este dinero "D", compra otros objetos "M" para su consumo, completando la fórmula de la siguiente manera:

$\mathrm{M}$ - D - M

70 En nuestro caso, por ejemplo, lana de oveja (M) se intercambia por dinero (D). Con el dinero de la venta se compran insumos de subsistencia para la familia (harina, grasa o aceite, verduras, etc.), o sea, otras mercancías (M).

Luego de esta primera fase, y ampliando el ciclo, aparece la producción, "P", que permite crear nuevos valores para acudir al mercado y de tal modo reiniciar el proceso. El ciclo entonces quedaría formulado así:

M - D - M ... P ... M - D - M

O sea: se producen mercancías "M". Con el dinero "D" obtenido por la venta de estas mercancías se adquieren otras mercancías " $\mathrm{M}$ ": harina, yerba, grasa, verduras o utensilios diversos necesarios tanto para la reproducción de la vida cotidiana como para las tareas productivas. Se reinicia entonces el ciclo productivo: se atiende a los nacimientos de nuevos animales, se los cría, se los protege del frío, la enfermedad y los predadores, se los alimenta y engorda, se los marca y/o señala, se propicia la preñez de las hembras y finalmente se los esquila o se los faena. En todo esto radica la producción "P". Y resulta en la obtención de una nueva mercancía "M" para volver al comienzo.

En ese punto el argumento de Gregory adquiere su densidad. ¿En qué condiciones sociales y geográficas se lleva adelante la producción "P"? ¿En qué lugar temporal y espacialmente situado? ¿Dónde sino en el territorio, el "bien supremo", the supreme good? Gregory señala entonces que para ciertos sujetos (en su propuesta, los campesinos de Bastar o Minipur en la India, o la aristocracia inglesa. Pero por qué no, diríamos nosotros, los crianceros mapuche de la Patagonia argentina), los bienes juegan un papel crucial en la producción de mercancías.

ducción ganadera de los crianceros mapuche se realiza en el territorio. Pero también en el territorio se anuda otro gran número de dimensiones de la vida social que, como hemos reseñado brevemente más arriba, hacen a la materialidad de la vida cotidiana en los distintos parajes rurales.

El territorio adquiere así una gran centralidad en las relaciones sociales. El anclaje de los ancestros y los pu newen (fuerzas o energías vitales que también habitan el territorio) que 
viven en interacción con los humanos, el rewe y la propia entidad familiar y residencial son el medio para la producción. La producción ("P") se realiza como una totalidad articulada en donde intervienen el alambre, la marca y la tijera de esquila, pero también los antepasados, las fuerzas extra-humanas del entorno, las trayectorias históricas, los Ngen (fuerzas que controlan a los pu newen), los familiares, los vecinos, el Juez de Paz y la Dirección de Ganadería. Todos anclados en el "bien supremo".

Parafraseando a Piero Sraffa (1966), Gregory dirá que "producen mercancías a través de bienes" (1997, p. 119). Parafraseando a Gregory, diremos que producen la subsistencia a través del territorio. Y la marca viene a intervenir -a requisito del Estado, de ciertas esferas del mercado y de los propios productores- en el vínculo entre el territorio y el "criancero" mapuche.

\section{Marca y territorio: tierra, territorio y propiedad: los "fiscaleros"}

Aún en los casos en que se les reconocieron legalmente tierras bajo la forma de "reservas" o "colonias indígenas" a fines del siglo XIX y comienzos del XX (Delrio, 2005; Martinelli, 2015), los pobladores mapuche de las regiones rurales de Chubut y Río Negro atravesaron $\mathrm{y}$ atraviesan en la actualidad una precaria situación en términos de tenencia y reconocimiento de su territorio.

Las figuras aplicadas por el Estado sobre la tierra son muy variadas e incluyen una mixtura de formas de propiedad que se solapan constantemente. Abarcan desde los títulos privados individuales hasta la propiedad colectiva, pasando por las que mantienen aún la figura de "reserva" y las que el Estado designa como "fiscales" en cualquiera de sus tres instancias: nacional, provincial o municipal.

En estos últimos casos la expresión de las tensiones que impone el registro de marcas y señales se hace en extremo evidente. Esto da pie al surgimiento de la categoría del "fiscalero", es decir, aquellos que ocupan y producen su subsistencia -con permiso- en tierras que el Estado designa como fiscales.

Por un lado los "fiscaleros" son un buen número de las unidades productivas de la región. Y por el otro representan una importante porción del territorio rural:

Para el caso de Río Negro las tierras fiscales constituyen el 30\% aproximadamente de toda la superficie de la región, ocupadas por 1.620 ocupantes fiscales, con un promedio de 2.000 has. por ocupante, aproximadamente.

Debido a que la unidad económica de esta zona es de aproximadamente 7.000 has., queda claro que la mayor cantidad de ocupantes son minifundistas, con una actividad que hoy solo les permite su subsistencia.

[...] La problemática de las tierras rurales en la provincia del Chubut es la misma que en la provincia de Río Negro (Sili y Li, 2012, pp. 69-70).

Como habíamos adelantado, el registro de la marca y el permiso para la marcación requieren del aval del Juez de Paz o la Dirección de Ganadería. Y uno de los requisitos para tal aval es la acreditación de la titularidad del territorio en que se cría al ganado.

Los propietarios privados individuales siguen las instancias burocráticas a partir de esa instancia, sean mapuche o no. El problema surge cuando la situación social de los productores difiere de la propuesta por el recorrido legal-institucional que prevé la Ley de Marcas y Señales. Allí aparece un nuevo sentido de la marca: aquel que indica, una y 
otra vez, que ese bien supremo, el territorio, ha sido arrebatado y no está bajo control. A la producción histórica del territorio como "tierra fiscal", elaborada por el Estado a partir de las llamadas "Campañas al Desierto" y extendida en tiempo y espacio a través de una multiplicidad de mecanismos, le corresponde la producción del miembro del pueblo mapuche como "fiscalero".

\section{La marca como significante de la expropiación histórica}

Cuando no se puede acreditar la titularidad o formas de tenencia del espacio territorial en los cánones que las instituciones estatales requieren (propietario, arrendatario, con pastaje o pastoreo, permisionario, con autorización), la alternativa es reconocerse como "fiscalero": ocupante precario de un lote fiscal. Con tal documento, que en Río Negro expide la Dirección de Tierras y en Chubut el Instituto Autárquico de Colonización y Fomento (IAC), se puede tramitar el boleto de marca o señal.

En este punto, en el caso específico de un "fiscalero" mapuche, avanzar con los trámites de marca implica simultáneamente reconocerse como miembro de un pueblo sin derechos sobre el territorio que histórica y efectivamente ocupa. Los mapuche pasan a ser "ocupantes precarios de tierras fiscales", portadores de un permiso estatal. No se les niega el boleto, en tanto se reconozcan "ocupantes precarios".

El territorio como bien supremo aparece así nuevamente intervenido por las regulaciones estatales. Aquel bien que supuestamente debe ser extraído de lo público, del intercambio y la exposición es, en cambio, objeto de los más mundanos trámites burocráticos. Las instituciones estatales tratan a los bienes mapuche fuera de su lógica histórica, imponiéndoles una racionalidad nueva.

87 En este proceso se abren, además, múltiples vericuetos y oportunidades para el ejercicio del poder: gestores, favores, líderes locales y agencias estatales se entrecruzan en la obtención de un permiso de ocupación o, para lo que nos interesa aquí de un boleto de marca. ${ }^{14}$ Pero en última instancia todos estos procesos se anclan en la falta de control autónomo de los pobladores mapuche en torno del territorio que habitan y trabajan.

La situación de fondo es, por supuesto, la expropiación histórica a que se ha sometido al pueblo mapuche a partir de las llamadas "Campañas al Desierto" a fines del siglo XIX y los procesos de despojo que, con sus características, atravesaron todo el siglo XX y las primeras décadas del XXI. Separados violentamente del territorio, el reasentamiento de los mapuche una vez concluidas las acciones militares se dio en condiciones impuestas, es decir, fuera de su control (Bonfil Batalla, 1988). Los mapuche se reasentaron sobre su propio territorio, pero en condiciones de enajenación: el territorio había sido expropiado y apropiado, será alambrado, vigilado por la policía y delimitado de acuerdo a las necesidades de un puerto lejano. Su acceso será gestionado por Direcciones de Tierras e Institutos de Colonización; para marcar a sus animales se verán forzados a decirse a sí mismos "fiscaleros". El territorio ya no les pertenece, y si acaso persisten allí es porque la gracia del Estado se los ha concedido.

89 La marca puede funcionar entonces como un índice de la enajenación sufrida por los mapuche. Es otro de los significados que puede sostener. 


\section{Marca y política: una experiencia de organizaciones etno-políticas}

En 2015, como parte de una demanda encarada por varias comunidades de Río Negro se logró el fallo "Comunidad mapuche Las Huaytekas c/provincia de Rio Negro s/ contencioso-administrativo s/medida cautelar (expte. 00503-13)". La justicia rionegrina obligó al Estado provincial a entregar los boletos de marca y señal a los productores sólo por el hecho de pertenecer al pueblo mapuche, sin que se vieran obligados a adscribirse como "fiscaleros" ni presentar permisos de ocupación.

Bajo esta obligación, en el año 2015, el gobernador Alberto Weretilneck dictó el decreto 270/15, por el cual permite a la población originaria acceder a los boletos de marcas y señales aún sin contar con un permiso de ocupación de tierras emitido por la Dirección de Tierras, siendo suficiente que la autoridad indígena certifique la posesión tradicional de la tierra.

La autoridad indígena, en este caso, era el Consejo de Desarrollo de Comunidades Indígenas (CODECI), órgano estatal-participativo creado por la ley 2.287. También el Consejo Asesor Indígena, (CAI) organización de base del pueblo mapuche con una larga trayectoria de acción en la zona, adquirió la potestad de auto-administrar el otorgamiento de boletos de marca y señal. Por supuesto, ninguna de estas dos entidades bastan para dar cuenta de la totalidad de estrategias y percepciones que sostiene un colectivo tan amplio, múltiple y diverso como el pueblo mapuche. Pero son las instituciones sobre las que recayó la síntesis de esta experiencia de organización y reclamo.

Ahora los crianceros podrían obtener boletos de marca y señal desde su sola identidad en tanto mapuche, sin verse obligados a reconocerse como "fiscaleros", ni tramitar permisos de ocupación, ni cosa alguna.

Es decir que en este proceso de disputa, que abarca tanto dimensiones territoriales como políticas y judiciales, dos logros se obtuvieron: que se pudiera tramitar boleto de señal y/ o marca por el sólo hecho de ser mapuche (además de los otros requisitos vinculados a los animales), sin tener que identificarse como "fiscalero"; y que la certificación de la pertenencia mapuche, además de ser otorgada por el ente legal representado por el CODECI, pudiera ser legitimada por el CAI sin intervención estatal.

Obviamente, esta nueva situación no es reparadora de los procesos atravesados por el pueblo mapuche ni hace que cesen las desigualdades que atraviesan su vida cotidiana y las actividades de producción de algunos de sus miembros. Pero es ciertamente un paso en las disputas vinculadas al control del territorio y una experiencia que se suma a las múltiples iniciativas que se llevan adelante desde distintas organizaciones y colectivos. En Chubut, en tanto, estos procesos no se han aún iniciado y la situación de quienes intentan obtener boletos de señal y marca desde su identidad indígena enfrentan los obstáculos que, hasta hace poco, aparecían en Río Negro.

Las marcas y señales pueden constituirse, entonces, también como un campo de disputas en el marco confrontaciones de orden político. 


\section{Palabras finales}

En el proceso de constitución social de los productores mapuche como poseedores de mercancías y propietarios privados de mercancías se articulan, como podemos verificar, una multiplicidad de procesos anudados a las marcas y señales.

La marca y la señal encarnan, al menos para muchos pobladores mapuche de Río Negro y Chubut, conjuntos de tensiones, contradicciones y referencias a procesos históricos de corto, mediano y largo plazo.

En el plano familiar y doméstico, las marcas y señales pueden expresar tanto establecimiento y reactualización de las redes de amistad y parentesco (como en los eventos de marcación y señalada) como etapas en el ciclo de los roles personales: de hijo a marido, o a productor adulto, con marca a su nombre.

3 Como parte de los dispositivos burocráticos, las marcas y señales son significantes de entramados institucionales: poderes legislativos, organismos de ejecución como juzgados de paz y direcciones de ganadería y agencias de control como las policías específicas encarnan las funciones de creación, ejecución y vigilancia de las normativas.

94 En el ámbito de las dinámicas mercantiles, las marcas y señales invitan a pensar en términos del proceso de producción, pero también en términos del proceso de identificación del propietario individual. Construir a la persona del propietario de las mercancías involucra a las dimensiones arriba mencionadas, pero también a los distintos agentes que intervienen en el proceso productivo.

Así, en el marco de la producción ganadera, la marca y la señal expresan los vínculos de las personas mapuche con el territorio, mediado por un extenso abanico de intervenciones estatales y no estatales que hacen a la vida común. Las políticas públicas, las agencias específicas de desarrollo rural, la familia, la comunidad, los antepasados, los seres extrahumanos que habitan el mundo mapuche son parte integrante del proceso productivo expresándose en el territorio como "bien supremo".

De allí que las vinculaciones entre marcas y señales y territorio revelen el desfasaje existente entre el proceso histórico atravesado por el pueblo mapuche (la enajenación de su territorio y autonomía política) y los dispositivos burocráticos que regulan las marcas y señales. La marca es, en este sentido, también un significante de esa expropiación. Y a la vez, como en el caso de la lucha legal para conseguir boletos desde la sola identidad como mapuche, un significante de las luchas políticas de algunas fracciones del pueblo mapuche y sus organizaciones.

97 Entonces, la lógica intrínseca de la mercancía, las relaciones de propiedad, los vínculos familiares y vecinales, los ciclos de expansión y contracción de las unidades domésticas y el rol de las esferas burocráticas y de control del Estado pueden verificarse en el proceso de analizar este complejo artefacto que se denomina "marca".

También tal artefacto podría pensarse en términos de una articulación entre las quemaduras y cortes en los cuerpos de los animales, los procesos históricos de enajenación territorial y política del pueblo mapuche, el ambiguo rol del Estado en tanto garante y obstáculo del vínculo entre propietario, animal y territorio y los avances obtenidos mediante la acción política y social de las organizaciones mapuche. 
99 significantes de estas disputas; y expresarían de maneras efectivas el balance de poder entre los actores involucrados. Al constituir a al "poseedor de mercancías" como "propietario privado" todos estos elementos entran en juego.

\section{BIBLIOGRAFÍA}

Balazote, A. y Radovich, J. C. (1995). Transiciones y fronteras agropecuarias en Norpatagonia. En H. Trinchero (Comp.), Producción doméstica y capital. Estudios desde la antropología económica, (pp. 63-79). Buenos Aires: Biblos.

Bechis, M. (2010). Piezas de Etnohistoria y Antropología Histórica. Buenos Aires: SAA.

Bendini, M., Tsakoumagkos, P. y Nogués, C. (2004). Los crianceros trashumantes del Neuquén. En M. Bendini y C. Alemany (Comps.), Crianceros y chacareros en la Patagonia, Cuaderno GESA 5, (pp. 23-39). Buenos Aires: La Colmena.

Bonfil Batalla, G. (1988). La teoría del control cultural en el estudio de los procesos étnicos, Anuario Antropológico/86, 13-53.

Briones, C. y Delrio, W. (2002) Patria sí, colonias también. Estrategias diferenciales de radicación de indígenas en Pampa y Patagonia (1885-1900). En A. Teruel, M. Lacarrieu y O. Jerez (Comps.), Fronteras, Ciudades y Estados, (pp. 45-78). Córdoba: Alción Editora.

Delrio, W. (2005). Memorias de expropiación. Sometimiento e incorporación indígena en la Patagonia (18722-1943). Bernal: Universidad Nacional de Quilmes.

Godelier, M. (1998 [1996]). El enigma del don. Barcelona: Paidós.

Gregory, C. A. (1982). Gifts and Commodities. Londres: Academic Press.

Gregory, C. A. (1997). Savage Money. Amsterdam: Harwood.

Lévi-Strauss, C. (2006). El campo de la antropología. En Antropología estructural, dos. Mito, sociedad, humanidades, (pp. 9-36). México: Siglo XXI.

Martínez Golletti, L. (2005). Marcas y señales, propiedad del ganado y Constitución Nacional. Academia Nacional de Derecho y Ciencias Sociales de Córdoba. http://www.acaderc.org.ar/doctrina/ articulos/artpropiedaddelganado [Consultado el 23-11-2018].

Martinelli, M. L. (2015). Las reservas indígenas en el departamento de Ñorquinco, Informe Final (2012-2015) para la Comisión Investigadora para el Relevamiento de Transferencia de Tierras Rurales en el ámbito de la Provincia de Río Negro (Ley 4.744). Universidad Nacional de Río Negro y Legislatura del Pueblo de la Provincia de Río Negro.

Maiztegui Martínez, H. (2017). La reforma de la ley 22.939, el Código Civil y quién regulará los nuevos medios de trazabilidad. La reglamentación nacional o provincial?. Ponencia en el IV Congreso Nacional de Derecho Agrario Provincial. Salta, 2017. UNLP y Universidad Católica de Salta. http://sedici.unlp.edu.ar/handle/10915/60435 [Consultado el 23-11-2018].

Marx, K. (2006 [1872]). El Capital. Crítica de la economía política. México: Siglo XXI. 
Mauss, M. (1980 [1925]). Essai sur le don. Forme et raison de l'échange dans les sociétés arquïques. En Sociologie et anthropologie, (pp. 143-279). París: PUF.

Sahlins, M. (1983 [1972]). Stone Age Economics. Londres: Tavistock. de Saussure, F. (1945). Curso de Lingüística General. Buenos Aires: Losada.

Sili, M. y Li, S. (2012). Las tierras fiscales en la Patagonia argentina. Un viejo problema irresuelto. Revista Huellas, 16, 54-77.

Sraffa, P. (1966). Producción de mercancías por medio de mercancías. Barcelona: Oikos.

Weiner, A. (1992). Inalienable Possessions. The Paradox of Keeping-While-Giving. Berkeley: University of California Press.

\section{Fuentes}

Censo Nacional de Población, 2010.

Ley Nacional $\mathrm{N}^{\circ} 22.939$

Ley Provincial N 1.645 (Río Negro).

Ley Provincial $N^{\circ}$ 4.113. (Chubut)

PROINDER (2013). Relevamiento y sistematización de problemas de tierra de los agricultores familiares en la Argentina. Secretaría de Agricultura Familiar. Ministerio de Agricultura.

\section{NOTAS}

1. Trabajamos sistemáticamente en esta zona desde 2009, aproximadamente, y desde hace varios años residimos en la región.

2. Los criterios censales para determinar la adscripción étnica pueden ser discutibles. Además, en 2010 la encuesta censal se hizo, a diferencia del Censo de 2001, sobre una muestra estadística. Sin embargo, son los datos más actualizados y sistemáticos con los que contamos.

3. Siempre y cuando se cuente con el territorio necesario para desarrollar esta práctica. Los campos de veranada suelen ubicarse en zonas altas que sólo se utilizan durante los meses más calurosos del año, para dejar descansar a los predios de invernada. De modo que esta dinámica requiere de arreos y extensiones territoriales amplias.

4. Si bien hay marcadas diferencias entre quienes habitan la zona cordillerana y quienes están establecidos en la meseta, por lo general las temperaturas extremas y las bajas precipitaciones hacen muy difíciles las tareas de cría y engorde. Hay zonas donde una producción racional y sustentable demanda cuatro hectáreas por cada cabeza de lanar.

5. Posiblemente deba leerse el proceso de unificación del sistema de marcas y señales como parte de la construcción de un Estado centralizado.

6. Ya vimos que existe la posibilidad de marcar mediante tinturas o tatuajes. También actualmente se introducen nuevas tecnologías que van desde chips vinculados a sistemas de geoposicionamiento hasta lectores láser. Sin embargo, para lo que conocemos en nuestra zona, la marca mediante hierro candente es ampliamente predominante.

7. A precios del año 2010, aproximadamente.

8. El Documento Nacional de Identidad (DNI) es una credencial de carácter universal que se utiliza en Argentina para identificar a las personas. Permite asociar huellas dactilares, nombre y fotografía de un individuo -entre otros datos- a un número de ocho cifras que se le asigna de manera permanente y que le será requerido incontables veces a lo largo de su vida, hasta para los trámites más nimios. 
9. Se refiere a la patente de los automotores.

10. Donde no hay oficina de Ganadería se suelen articular entre los municipios y Juzgados de Paz para la gestión de los boletos.

11. Aquí parte de nuestra información proviene, además de las leyes y reglamentaciones respectivas, del propio Juzgado de Paz de Esquel, Chubut a cuyo personal y titular agradecemos por la buena predisposición para colaborar con este trabajo.

12. Los funcionarios del SENASA, que suelen trabajar coordinadamente con la Gendarmería Nacional, pueden indicar el decomiso y la destrucción de objetos de origen animal o vegetal que no cumplen los requisitos de sanidad requeridos.

13. Los crianceros mapuche suelen ser propietarios de lo que producen, aun cuando su producción se lleve a cabo en territorios comunales.

14. Incluso pueden darse ejercicios donde el propio boleto de señal puede ser utilizado como instrumento jurídico para demostrar un poblamiento antiguo o una ocupación pasada.

\section{RESÚMENES}

Proponemos un análisis de los procesos de marca y señal del ganado y sus implicancias para los pobladores mapuche de Río Negro y Chubut en la actualidad.

Sostendremos una perspectiva que intenta integrar los desarrollos de la antropología económica con una mirada interpretativa desde el punto de vista etnográfico. Plantearemos que las marcas y señales constituyen significantes de distintas tensiones, pujas, contradicciones y disputas que incluyen a la vecindad, la familia, los procesos mercantiles, el Estado y las organizaciones mapuche.

Y que también expresan un conjunto de situaciones políticas e históricas entre las que se cuentan el enajenamiento y expropiación que se construyen en torno del territorio mapuche y la figura del "fiscalero".

We propose an analysis of the cattle brand and signal processes and their implications for the Mapuche inhabitants of Río Negro and Chubut today.

We will hold a perspective that attempts to integrate the developments of economic anthropology and an interpretive view from the ethnographic point of view.

We will propose that the marks and signs are signifiers of different tensions, bids, contradictions and disputes that include family, neighborhood the mercantile processes, the State, the Mapuche settlers and their organizations.

And they also express a set of political and historical situations among which are the alienation and expropriation that are built around the Mapuche territory and the figure of the "fiscalero".

\section{ÍNDICE}

Keywords: Brand and signals; mapuche settlers; signifiers; territory

Palabras claves: Marcas y señales; pobladores mapuche; significantes; territorio 


\section{AUTOR}

\section{HERNÁN HORACIO SCHIAFFINI}

Consejo Nacional de Investigaciones Científicas y Técnicas, Universidad Nacional de la Patagonia San Juan Bosco-Argentina

Correo electrónico: hernanschiaffini@gmail.com 